\title{
Inhibition of GLUT-I expression and the PI3K/Akt pathway to enhance the chemosensitivity of laryngeal carcinoma cells in vitro
}

This article was published in the following Dove Press journal:

OncoTargets and Therapy

\author{
Tao Jiang' \\ Min-Li Zhou ${ }^{2}$ \\ Jun Fan ${ }^{3}$
}

'Department of Otolaryngology, Yinzhou People's Hospital of Ningbo City Zhejiang Province, Zhejiang, China; ${ }^{2}$ Department of Otolaryngology, ${ }^{3}$ State Key Laboratory for Diagnosis and Treatment of Infectious Diseases, The First Affiliated Hospital, College of Medicine Zhejiang University, Zhejiang, China
Correspondence: Tao Jiang Department of Otolaryngology, Yinzhou People's Hospital of Ningbo City Zhejiang Province, 25I Baizhang East Road,

Zhejiang 315040 , China

Tel +86 I38 844592 I2

Email jiangtaoningbo@।63.com
Background: The mechanism of chemoresistance remains unknown. Here, we investigated if glucose transporter-1 (GLUT-1) and PI3K/Akt pathways are associated with the sensitivity to cisplatin in Hep-2 laryngeal carcinoma cells and whether the inhibition of GLUT-1 and the PI3K/Akt pathways enhances the chemosensitivity of Hep-2 cells.

Method: The effects of inhibiting GLUT-1 by a GLUT-1 siRNA, and PI3K/Akt by Ly294002, on cisplatin-induced effects were assessed in vitro.

Results: GLUT-1 siRNA and cisplatin showed a synergistic effect in inhibiting the proliferation of Hep-2. LY294002 and cisplatin also showed a synergistic effect in inhibiting the proliferation of Hep-2. GLUT-1 siRNA, LY294002 and cisplatin effectively inhibited the mRNA expressions and protein expressions of GLUT-1, Akt, PI3k and HIF-1 $\alpha$ in Hep- 2 cells. Furthermore, GLUT-1 siRNA and cisplatin demonstrated a synergism to inhibit the mRNA expression of HIF-1 $\alpha$. Moreover, it was found in this study that GLUT-1 siRNA, LY294002 and cisplatin induced the suppression of the cell cycle at G1/G2 and the increasing of apoptosis in Hep-2 cells.

Conclusion: This study showed that inhibiting GLUT-1, by a GLUT-1 siRNA and inhibiting PI3K/Akt by Ly294002, could suppress the proliferation of Hep-2 alone and together with cisplatin synergistically, which demonstrated the potentials to treat laryngeal carcinoma in the future therapy. Additionally, the synergistic effect between LY294002 and cisplatin to suppress the proliferation of Hep-2 might not be from GLUT-1, Akt, PI3k and HIF-1 $\alpha$; the synergistic effect between GLUT-1 siRNA and cisplatin to suppress the proliferation of Hep-2 might not be from GLUT-1, Akt and PI3k and might be more or less related to HIF-1 $\alpha$.

Keywords: laryngeal carcinoma, RNA interference, glucose transporter-1, PI3K/Akt pathway, cisplatin, chemosensitivity

\section{Introduction}

Although promising treatments preserving laryngeal function, including chemotherapy and radiotherapy, have been advanced, the overall survival rate of patients with laryngeal carcinoma remains poor. ${ }^{1,2}$ One possible mechanism may be the development of chemo-radioresistance in laryngeal carcinoma. Studies have demonstrated that hypoxia plays a key role in laryngeal carcinoma radioresistance: ${ }^{3-6}$ 1) Glucose transporter-1 (GLUT-1), as an important hypoxic marker, has also been found to have an important role in laryngeal carcinoma radiosensitivity, and inhibition of GLUT-1 expression may enhance the radiosensitivity of laryngeal carcinoma;,6-9 2) HIF-1 $\alpha$, as another important hypoxic marker, has also been found to have an important role in laryngeal carcinoma radiosensitivity, and inhibition of HIF- $1 \alpha$ expression may enhance the radiosensitivity of laryngeal carcinoma. ${ }^{2}$ However, whether GLUT-1 or 
HIF- $1 \alpha$ is involved in chemosensitivity in laryngeal carcinoma remains unknown.

The phosphatidylinositol 3-kinase/protein kinase B (PI3K/ Akt) signaling pathway has been demonstrated to play an important role in the regulation of GLUT-1 and HIF-1 $\alpha$ expressions. ${ }^{10,11}$ The PI3K/Akt pathway is involved in the chemo-radiosensitivity of other malignant tumors. ${ }^{12-14}$ In laryngeal carcinoma, we found that GLUT-1 expression, via the PI3K/Akt pathway, plays a role in radiosensitivity, and co-inhibits the GLUT-1 expression and the PI3K/Akt pathway enhanced the radiosensitivity of laryngeal carcinoma. ${ }^{6,7}$ However, whether the expression of GLUT-1 or HIF-1 $\alpha$, via the PI3K/Akt pathway, is also involved in the chemosensitivity of laryngeal carcinoma is still unknown.

Cisplatin is a frequently-used chemotherapeutic drug for head and neck carcinomas; it may inhibit DNA replication and harm cell membrane structures. ${ }^{15,16}$ However, the development of resistance limits the clinical utility of cisplatin. ${ }^{17-19}$ The expression of GLUT-1 was shown to be related to cisplatin resistance. Moreover, inhibition of GLUT-1 expression may enhance sensitivity to cisplatin. ${ }^{17-19}$ Some research studies have also demonstrated that the PI3K/Akt pathway may be responsible for cisplatin resistance, and suppression of the PI3K/Akt pathway may enhance some solid tumors to be sensitive to cisplatin. ${ }^{20-22}$ Only our previous study examined the roles of expression of GLUT-1 and the PI3K/Akt pathway in cisplatin resistance of laryngeal cancer. ${ }^{17} \mathrm{We}$ found that resistance to or insensitivity of Hep- 2 cells to cisplatin may be related to the expression of GLUT-1, p-Akt protein and apigenin, which is a natural phytoestrogen flavonoid, may suppress the GLUT-1 expression and p-Akt expression non-specifically to improve the sensitivity of cisplatin. ${ }^{17}$ For HIF- $1 \alpha$, it was found that Sentrin/SUMO-specific protease 1 (SENP1) positively regulated the expression of HIF-1 $\alpha$ by deSUMOylation and weakened the sensitivity of hypoxic ovarian cancer cells to cisplatin, indicating that SENP1 is a positive regulator of HIF-1 $\alpha$ and plays a negative role in ovarian cancer chemotherapy. ${ }^{23}$

In this study, we systematically investigated the possible synergistic effects between inhibiting GLUT-1 by a GLUT-1 siRNA and cisplatin and between inhibiting PI3K/Akt by the inhibitor Ly294002 and cisplatin on the proliferation, the expressions of GLUT-1, Akt, PI3K and HIF-1 $\alpha$ in laryngeal carcinoma cells (Hep-2), to help in the development of the better therapy for laryngeal carcinoma.

\section{Materials and methods Ethics statement}

This investigation was conducted in accordance with the appropriate ethical standards. It was approved by a review board of Yinzhou People's Hospital of Ningbo City Zhejiang Province, China.

\section{Reagents}

The Hep-2 laryngeal carcinoma cell line was obtained from the Cell Research Institute of the Chinese Academy of Sciences (Shanghai, China). Cisplatin and Ly294002 were purchased from Sigma-Aldrich Co. (St Louis, MO, USA). The reverse transcription (RT) "Fast Quant RT" kit (supplied with gDNase; cat. no \#KR106-2), Trizol (cat: ET111-01), chloroform, isopropyl alcohol, and RNA dissolving liquid (cat: ET111-02) were purchased from Biogot Technology, Co., Ltd. (Nanjing, China). A primary antibody against GLUT-1 was purchased from Santa Cruz Biotechnology Inc. (Dallas, TX, USA). Secondary antibodies, donkey anti-rabbit and donkey anti-mouse, cell lysis reagents, the SuperSignal West Femto Kit and phenylmethanesulfonyl fluoride were purchased from Pierce (Rockford, IL, USA). Primers and Lipofectamine 2000 were purchased from Thermo Fisher Scientific (Waltham, MA, USA). The sequence of the entire coding region of GLUT-1 was obtained from GenBank, and primers were designed using the ClustalX and Omega 2.0 Applied Software. The Cell Counting Kit-8 (CCK-8) kit was purchased from Dojindo (Tokyo, Japan).

\section{Design and transfection of GLUT-I siRNA}

GLUT-1 siRNA was used to silence GLUT-1 expression in Hep-2 cells. siRNAs targeting the GLUT-1 sequence were designed by Shanghai GenePharma Co., Ltd. (Shanghai, China). The GLUT-1 or negative control (NC) siRNAs were then cloned into viral vectors, and lentiviruses carrying GLUT-1 and NC siRNAs were synthesized by Shanghai GenePharma Co., Ltd. GLUT-1 siRNA was transiently transfected into Hep-2 cells to deplete GLUT-1 expression. The efficiency of transient transfection was estimated with the fluorescence in situ RNA hybridization method and the brief was: 1) after the transient transfection, the cells were washed with PBS and fixed with paraformaldehyde; 2) the fixed cells were washed and penetrated with Triton-X-100;3) the resultant was then washed with PBS and incubated with the solution containing the probe with the fluorescent dye (6-carboxy-fluorescein); 4) after washing, the cells were observed under the inverted fluorescent microscope; 5) the transfection efficiency was estimated according to the range and intensity of the fluorescent signal. In this way, we found that the transfection efficiency was $65 \%-80 \%$. Screening and identification of transfectants were achieved using real-time RT polymerase chain reaction ( $\left.\mathrm{RT}^{2}-\mathrm{PCR}\right)$. 


\section{Groups}

In total, the following eight groups were analyzed: Hep-2, Hep2-siRNA ${ }_{\mathrm{NC}}$, Hep2-siRNA $_{\text {GLUT-1 }}$, Hep2+LY294002, Hep$2+$ cisplatin, Hep2-siRNA ${ }_{\mathrm{NC}}+$ cisplatin, Hep2-siRNA $\mathrm{GLUT}_{-1}+$ cisplatin, and Hep-2+Ly294002+cisplatin.

\section{Cell culturing}

Hep-2 cells were cultured in 10\% FBS and RPMI 1640 medium (Thermo Fisher Scientific), $2 \mathrm{mM}$ L-glutamine, $100 \mathrm{U} / \mathrm{mL}$ penicillin, and $100 \mathrm{~g} / \mathrm{mL}$ streptomycin at $37^{\circ} \mathrm{C}$ in a $5 \% \mathrm{CO}_{2}$ atmosphere. The cells were digested in $0.25 \%$ trypsin $+0.02 \%$ EDTA. Cells were trypsinized and harvested after reaching $80 \%-90 \%$ confluence.

\section{GLUT-I siRNA transfection, treatment with cisplatin and Ly294002}

Hep-2 cells were seeded in 96-well plates 24 hours before transfection, and $2 \mathrm{~mL}$ RPMI 1640 medium was added. Upon reaching $60 \%-70 \%$ confluency, the cells were used in experiments. Pure GLUT-1 siRNA $(4 \mu \mathrm{g})$ and control siRNA were diluted in $250 \mu \mathrm{L}$ Opti-MEMI Reduced Serum medium. Lipofectamine 2000 was mixed gently and diluted in $250 \mu \mathrm{L}$ Opti-MEMI Reduced Serum medium for 5 minutes. Diluted siRNA- $_{\text {GLUT-1 }}$ or siRNA ${ }_{\mathrm{NC}}$ was mixed gently with Lipofectamine 2000 for 20 minutes at room temperature. Then, the diluted siRNA- ${ }_{\text {GLUT-1 }}$ or siRNA ${ }_{\mathrm{NC}}$ and Lipofectamine 2000 were added to cultured Hep- 2 cells at room temperature and cultured for 8 hours. The Hep- 2 cells were cultured for a further 24 hours after refreshing the medium, and $20 \mu \mathrm{M}$ LY294002 and $3 \mu \mathrm{g} / \mathrm{mL}$ cisplatin were added for another 24 hours and 48 hours, respectively.

\section{CCK-8 assay}

Cells from each group were cultured with $10 \mu \mathrm{L} \mathrm{CCK}$ solution for 2 hours. The absorption at $450 \mathrm{~nm}$ was measured using a Spectra Plus microplate reader (Molecular Devices LLC, Sunnyvale, CA, USA). The relative cell inhibition rate (IR) (\%) was calculated by the following formula: $100 \%-$ (sample absorption/control mean absorption) $\times 100 \%$.

\section{Analysis of apoptosis and cell cycle by flow cytometry}

Flow cytometry was performed as described previously. ${ }^{8}$ Cell cultures from each group were digested with trypsin without EDTA and then centrifuged (2,000 rpm). The cells were collected and washed with $500 \mu \mathrm{L}$ PBS. Then, $400 \mu \mathrm{L}$ Binding Buffer (M3036) was added. Next, $5 \mu \mathrm{L}$ annexin V-FITC (M3031) was added, and the mixture was incubated for 5 minutes in the dark. The data were analyzed using ModFit LT software (Becton Dickinson, Mountain View, CA, USA). Each experiment was performed in triplicate.

\section{Detection of GLUT-I,AKT, PI3K, and HIF-I $\alpha$ mRNA expression by RT ${ }^{2}$-PCR}

$\mathrm{RT}^{2}$-PCR was performed as described previously. ${ }^{8,17}$ Total RNA was extracted from cell cultures from each group, and mRNA was reverse transcribed. The mRNA RT reaction contained $2 \mu \mathrm{L}$ RNA template and $5 \mu \mathrm{L} 25 \mu \mathrm{M}$ primers, which were heated to $70^{\circ} \mathrm{C}$ for 5 minutes before adding to the following: $10 \mu \mathrm{L} 2 \times \mathrm{RT}$ buffer, $3 \mu \mathrm{L} 375 \mathrm{nM}$ dNTPs, $0.4 \mu \mathrm{L} 4 \mathrm{U} / \mu \mathrm{L}$ MMLV reverse transcriptase, and $0.15 \mu \mathrm{L}$ $0.3 \mathrm{U} / \mu \mathrm{L}$ RNasin before incubation at $37^{\circ} \mathrm{C}$ for 60 minutes and $85^{\circ} \mathrm{C}$ for 10 minutes. Then, $\mathrm{RT}^{2}$-PCR was set up containing $20 \mu \mathrm{L}$ mRNA, $10 \mu \mathrm{L} 2 \times$ quantification PCR Master Mix, $0.08 \mu \mathrm{L} 0.08 \mu \mathrm{M}$ forward primer, $0.08 \mu \mathrm{L}$ $0.08 \mu \mathrm{M}$ reverse primer, $2 \mu \mathrm{L}$ template, $0.4 \mu \mathrm{L}$ Taq DNA polymerase, and deionized water. The $\mathrm{RT}^{2}$-PCR reaction conditions were denaturation at $95^{\circ} \mathrm{C}$ for 3 minutes, followed by 40 cycles of $95^{\circ} \mathrm{C}$ for 30 seconds and $62^{\circ} \mathrm{C}$ for 40 seconds. Each reaction was run three times. GLUT-1, AKT, PPIK, HIF- $1 \alpha$ and GAPDH forward and reverse primers were 5'-GTCAACACGGCCTTCACTG-3' and 5'-GGTCATGAGTATGGCACAACC-3' for GLUT-1, 5'-GCAGCACGTGTACGAGAAGA-3' and 5'-GGTGTC AGTCTCCGACGTG-3' for AKT, 5'-GGGGATGATT TACGGCAAGATA- $3^{\prime}$ and 5'-CACCACCTCAATAAG TCCCACA-3' for PPIK, 5'-GAAAGCGCAAGTCTTC

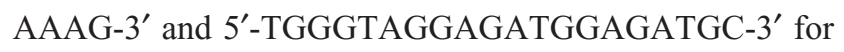
HIF- $1 \alpha$, and $5^{\prime}$-TGTTGCCATCAATGACCCCTT- $3^{\prime}$ and 5'-CTCCCACGACGTACTCAGCG-3' for GAPDH (control), respectively. The sizes of the PCR products were $111 \mathrm{bp}$ (GLUT-1), 67 bp (AKT), 144 bp (PI3K), 167 bp (HIF-1 $\alpha$ ), and 202 bp (GAPDH).

\section{Detection of GLUT-I,AKT, PI3K, and HIF-I $\alpha$ protein levels in Hep-2 cells}

Briefly, ${ }^{17}$ protein samples from cell cultures from each group were added to $4 \times$ sodium dodecyl sulfate (SDS) buffer, boiled for 10 minutes, and centrifuged (1,200 rpm, 1 minute). The proteins were separated by SDS-polyacrylamide gel electrophoresis. After electrophoresis, the proteins were transferred to a polyvinylidene difluoride (PVDF) membrane (EMD Millipore, Billerica, MA, USA). Primary antibodies against the following proteins were added to the membrane and incubated at $4^{\circ} \mathrm{C}$ overnight: GLUT-1 (1:800; Proteintech Group, Chicago, IL, USA), p-AKT (1:800; 
Proteintech Group), AKT (1:800; Proteintech Group), PI3K (1:800; Proteintech Group), HIF-1 $\alpha$ (1:800; Proteintech Group) and GAPDH (1:800; Proteintech Group). The PVDF membrane was washed with TBST buffer three times for 10 minutes. Secondary antibodies were added and incubated, and the membrane was washed with PBST buffer three times. The PVDF membrane was placed on a color plate, incubated with solutions $A$ and $B$ from the enhanced chemiluminescence assay kit (Beyotime Biological Technology Co. Ltd., Nanjing, China), and exposed to X-ray film. Semi-quantitatively using the ChemiDoc XRS + System (Bio-Rad Laboratories Inc., Hercules, CA, USA) analyzed the expression of proteins.

\section{Statistical analyses}

Data were presented in mean \pm SD. SPSS software (ver. 24.0 for Windows; SPSS Inc., Chicago, IL, USA) was used for all statistical analyses: 1) for the comparison between two groups, the Student's independent sample $t$-test was used; 2) for the analysis of the synergistic effect between two factors, the factor analysis was used. $P$-value less than 0.05 was considered to be statistically significant.

\section{Results}

\section{Effects of siRNA- ${ }_{\text {GLUT-I }}$ and LY294002 on the proliferation of Hep-2 cells after treatment with cisplatin}

Before treatment with cisplatin, the survival rates of cells in the siRNA- ${ }_{\text {GLUT-1 }}$ and LY294002 groups were decreased significantly at 24 hours and 48 hours compared with the control group and the siRNA- ${ }_{\mathrm{NC}}$ groups $(P<0.05$; Figure 1$)$. The proliferation of cells in each group was decreased markedly at 24 hours and 48 hours treated by cisplatin compared with before treatment $(P<0.05)$. The survival rates of cells in the siRNA- ${ }_{\text {GLUT-1 }}+$ cisplatin and LY294002+ cisplatin groups were decreased significantly at 24 hours and 48 hours compared with cells in the siRNA-GLUT-1 group, LY294002 and cisplatin group, respectively (for all, $P<0.05$; Figure 1). The factor analyses showed that for the inhibitory effect on the proliferation of Hep-2, there were synergistic effects between siRNA-GLUT-1 and cisplatin and between LY294002 and cisplatin. These findings revealed that siRNA- ${ }_{\text {GLUT-1 }}$ and LY294002 could enhance the inhibitory effect of cisplatin on the proliferation of Hep-2 cells, respectively.

\section{Effects of siRNA- ${ }_{\text {GLUT-I }}$ and LY294002 on apoptosis and cell cycle in Hep-2 cells after treatment with cisplatin}

Before the cisplatin treatment, the apoptotic rates of cells in the siRNA- ${ }_{\text {GLUT-1 }}$ and LY294002 groups were increased markedly at 24 hours and 48 hours compared with the Hep-2 cell and siRNA- ${ }_{\text {NC }}$ groups $(P<0.05$; Figure 2$)$. The early apoptotic cell number was increased markedly in the siRNA- $_{\text {GLUT-1 }}$ group, and that of late apoptotic cells was increased markedly in the LY294002 group. After the cisplatin treatment, the apoptotic rates in both groups were increased significantly at 24 hours and 48 hours $(P<0.05$; Figure 2). The apoptotic rates of cells in the siRNA- ${ }_{\text {GLUT-1 }}+$ cisplatin and LY294002+ cisplatin groups were increased markedly at 24 hours and 48 hours compared with cells in the cisplatin group ( $P<0.05$; Figure 2$)$. These findings show that siRNA- $_{\text {GLUT-1 }}$ and LY294002 enhance the cisplatin-increased apoptotic rate in laryngeal carcinoma Hep-2 cells.

After the cisplatin treatment, the population of cells in the G1/G2 phase was reduced markedly. siRNA- ${ }_{\text {GLUT-1 }}+$ cisplatin significantly decreased the population of cells in the $\mathrm{G} 1 / \mathrm{G} 2$ phase compared with cisplatin or siRNA- ${ }_{\text {GLUT-1 }}$ $(P<0.01$; Figure 3$)$. The population of Hep-2 cells treated with LY294002+cisplatin in the G1/G2 phase was increased
A

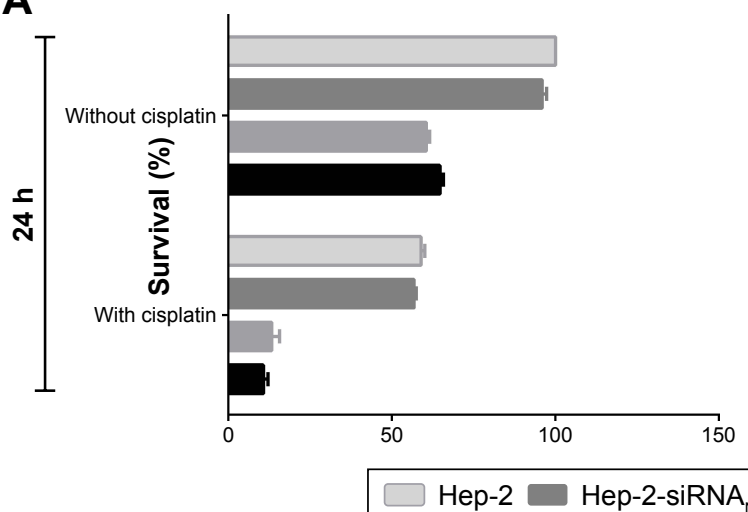

B

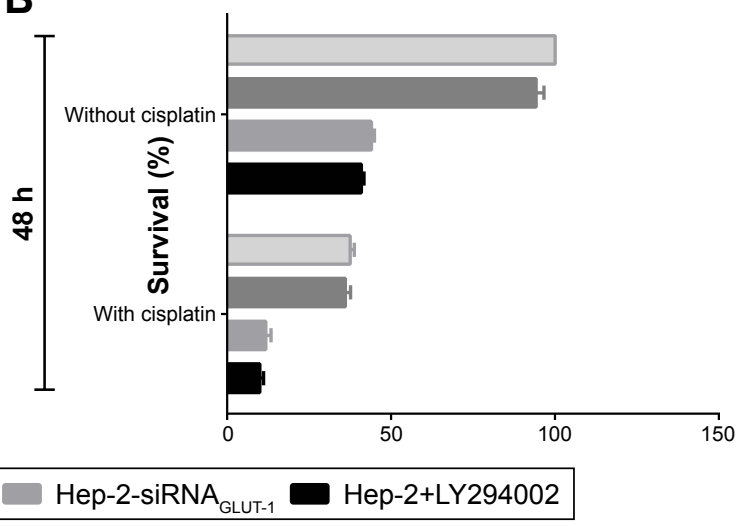

Figure I The survival rates of cells in the siRNA- ${ }_{\text {GLUT-I }}+$ cisplatin and LY294002+ cisplatin groups were decreased significantly at 24 hours (A) and 48 hours (B) compared with cells in the cisplatin group. 


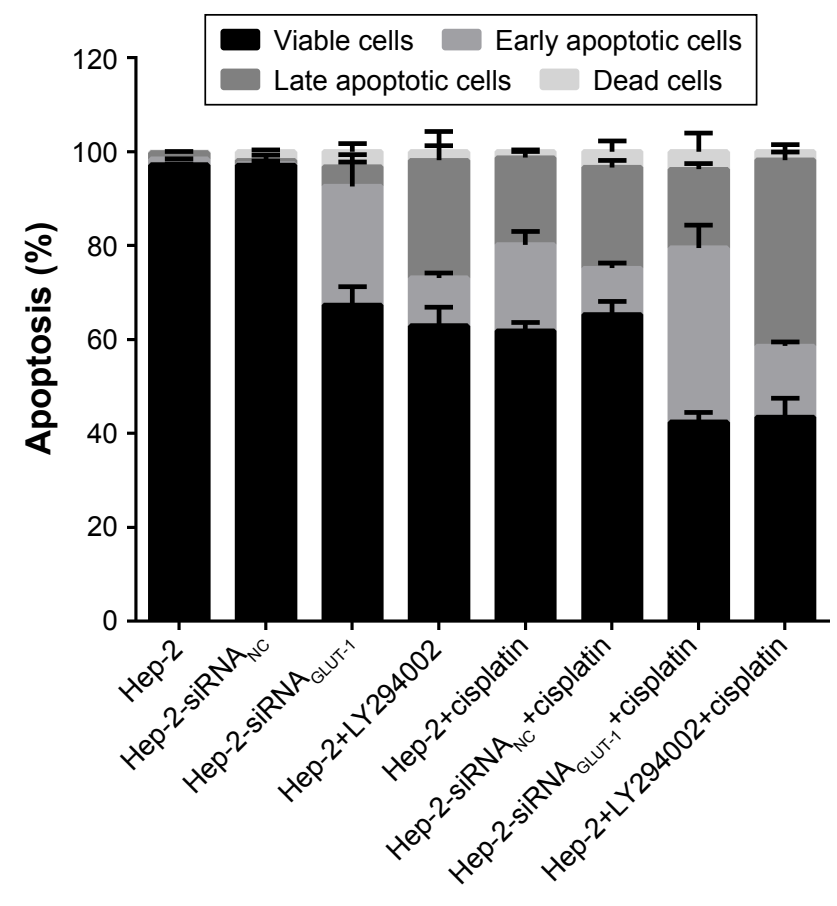

Figure 2 The apoptotic rates of cells in the siRNA- ${ }_{\text {GLUT.I }}+$ cisplatin and LY294002+ cisplatin groups were increased significantly at 24 hours and 48 hours compared with cells in the cisplatin group.

markedly than those in the untreated Hep-2 cells. LY294002 markedly reduced the population of cells in the $\mathrm{G} 1 / \mathrm{G} 2$ phase compared with cisplatin or LY294002 $(P<0.05$; Figure 3).

The abovementioned findings suggested that the synergistic effects between siRNA- ${ }_{\text {GLUT-1 }}$ and cisplatin and

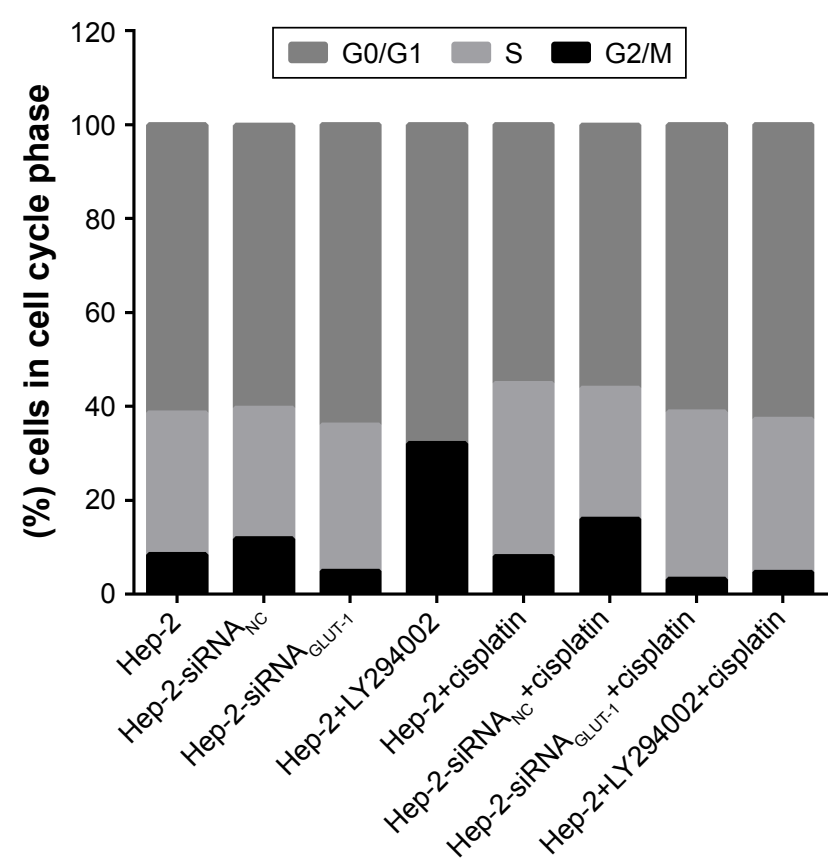

Figure 3 siRNA- $_{\text {GLUT-I }}+$ cisplatin significantly decreased the number of cells in the GI/G2 phase compared with cisplatin or siRNA- ${ }_{\text {GLUT-1 }}$, and LY294002 significantly decreased the number of cells in the GI/G2 phase compared with cisplatin or LY294002. between LY294002 and cisplatin might be at least partly from their synergistic effects on the apoptotic rate and the G1/G2 cell cycle arrest.

Effects of siRNAand LY294002 on GLUT-I, p-Akt, PI3K, and HIF-I $\alpha$ mRNA levels in Hep-2 cells after treatment with cisplatin

siRNA- ${ }_{\text {GLUT-1 }}$, cisplatin, siRNA ${ }_{\text {GLUT-1 }}+$ cisplatin, and LY294002+cisplatin significantly inhibited GLUT-1 and HIF-1 $\alpha$ mRNA expression in Hep-2 cells compared with the control group $(P<0.05$; Figure $4 \mathrm{~A}$ and $\mathrm{B})$. siRNA $_{\mathrm{GLUT}-1}+$ cisplatin and LY294002+cisplatin significantly inhibited GLUT-1 and HIF- $1 \alpha$ mRNA expression in Hep- 2 cells compared with the cisplatin group $(P<0.001$; Figure $4 \mathrm{~A}$ and $\mathrm{B})$.

LY294002 and LY294002+cisplatin significantly inhibited p-AKT mRNA expression in Hep-2 cells compared with the control group ( $P=0.03$ and 0.019 , respectively; Figure 4C). LY294002+cisplatin significantly inhibited p-AKT mRNA expression in Hep-2 cells compared with cisplatin alone and LY294002 alone ( $P=0.001$ and 0.001 , respectively; Figure 4C). siRNA $_{\text {GLUT-1 }}$, cisplatin and siRNA ${ }_{\text {GLUT-1 }}+$ cisplatin did not effect the expression of p-AKT mRNA in Hep-2 cells compared with the control $(P>0.05)$.

LY294002 and LY294002+cisplatin significantly inhibited PI3K mRNA expression in Hep-2 cells compared with the control group $(P<0.05$; Figure 4D). LY294002+cisplatin significantly inhibited PI3K mRNA expression in Hep-2 cells compared with cisplatin alone ( $P=0.007$; Figure 4D). siRNAGLUT-1 and cisplatin did not effect the expression of PI3K mRNA in Hep-2 cells compared with the control group $(P>0.05)$.

The factor analyses revealed that there were no synergistic effects between LY294002 and cisplatin on the mRNA expression of GLUT-1, Akt, PI3K and HIF-1 $\alpha$ and there were no synergistic effects between siRNA ${ }_{\text {GLUT-1 }}$ and cisplatin on the mRNA expression of GLUT-1, Akt and PI3K and there were synergistic effects between siRNA ${ }_{\text {GLUT-1 }}$ and cisplatin on the mRNA expression of HIF- $1 \alpha$.

\section{Effects of siRNA- ${ }_{\text {GLUT-I }}$ and LY294002 on} GLUT-I, p-Akt, PI3K, and HIF-I $\alpha$ protein levels in Hep-2 cells after treatment with cisplatin

siRNA- ${ }_{\text {GLUT-1 }}$, cisplatin, siRNA ${ }_{\text {GLUT-1 }}+$ cisplatin and LY294002+cisplatin inhibited GLUT-1 and HIF-1 $\alpha$ protein levels in Hep-2 cell compared with the control group (Figure 5). siRNA ${ }_{\text {GLUT-1 }}+$ cisplatin and LY294002+cisplatin significantly inhibited GLUT-1 and HIF-1 $\alpha$ protein levels 

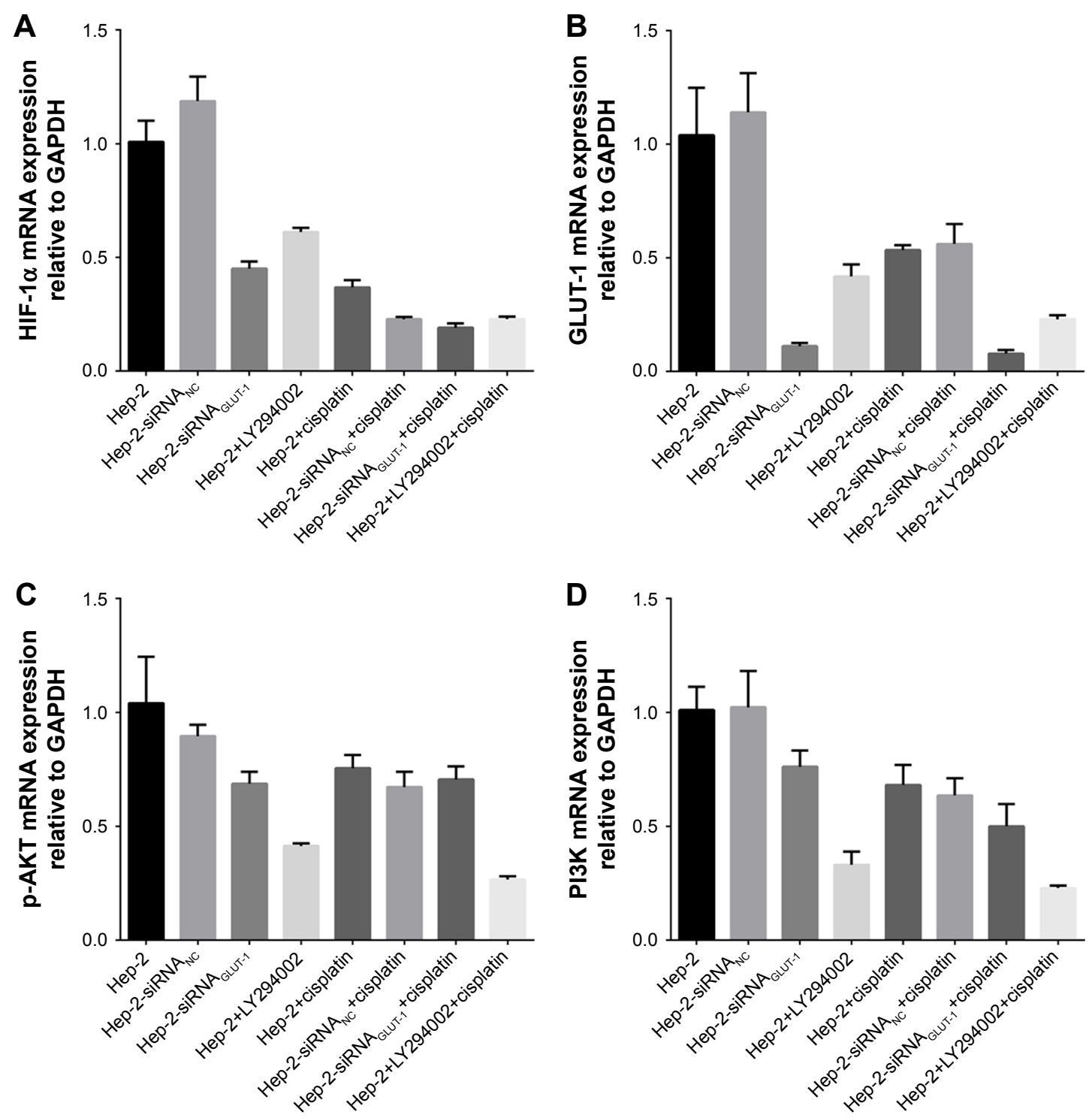

Figure 4 Effects of siRNA-GLUT-I and LY294002 on GLUT-I, p-Akt, PI3K, and HIF-I $\alpha$ mRNA levels in Hep-2 cells after treatment with cisplatin.

Notes: siRNA ${ }_{\text {GLUT-I }}+$ cisplatin and LY294002+cisplatin significantly inhibited GLUT-I (A) and HIF-I $\alpha$ mRNA (B) expression in Hep-2 cells compared with the cisplatin group. (C): LY294002+cisplatin significantly inhibited p-AKT mRNA expression in Hep-2 cells compared with cisplatin alone and LY294002 alone. (D). LY294002+cisplatin significantly inhibited PI3K mRNA expression in Hep-2 cells compared with cisplatin alone.

in Hep-2 cells compared with cisplatin alone (Figure 5). LY294002 and LY294002+cisplatin inhibited p-AKT and PI3K protein levels in Hep-2 cells compared with the control group. LY294002+cisplatin significantly inhibited p-AKT and PI3K protein levels in Hep-2 cells compared with cisplatin alone and LY294002 alone (Figure 5).

\section{Discussion}

The rapid proliferation of malignant tumors requires high levels of energy. Warburg effect is an anomalous characteristic of cancer cells, in which they consume a large amount of glucose and favor aerobic glycolysis over oxidative phosphorylation even in the presence of oxygen. ${ }^{24}$ GLUT-1 and HIF- $1 \alpha$ are key enzymes that mediate glucose metabolism in tumorigenesis. ${ }^{25,26}$ Overexpression of GLUT-1 has been demonstrated to be associated with recurrence, poor survival, metastasis and chemo-radioresistance in malignant tumors, ${ }^{27,28}$ including laryngeal carcinoma. ${ }^{29,30}$ Our previous studies have found that there were relationships between GLUT-1expression and radioresistance of laryngeal carcinoma and that inhibition the expression of GLUT-1 may enhance the radiosensitivity of laryngeal carcinoma., ${ }^{2,6-9}$ The mechanism may involve the activated PI3K/Akt pathway, which regulates GLUT-1expression. It has been found that specific inhibitors of the PI3K/Akt pathway (eg, Ly294002, Wortmannin) reduce GLUT-1expression and improve the radiosensitivity of laryngeal carcinoma. There is only one previous report about the expression of GLUT-1 and chemoresistance in laryngeal 


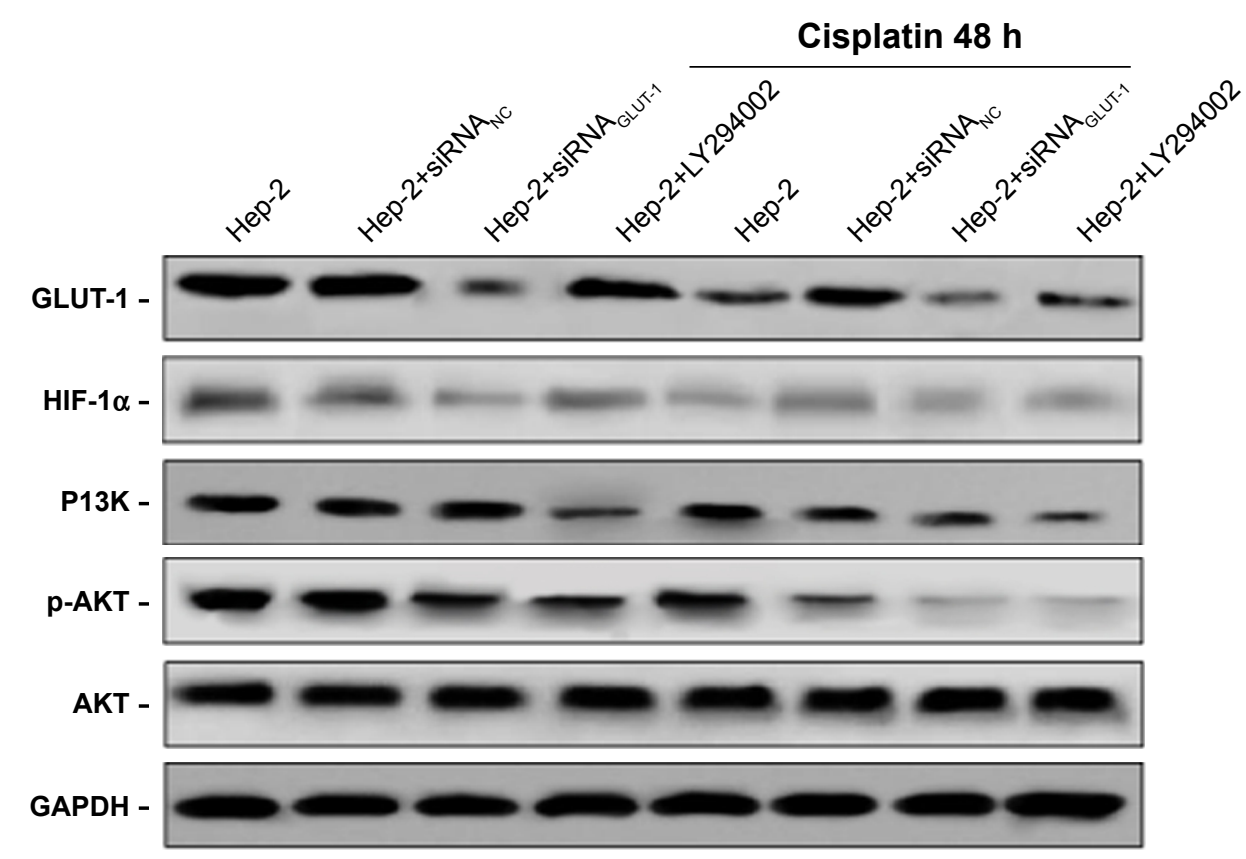

Figure 5 Effects of siRNA- ${ }_{\text {GLUT-I }}$ and LY294002 on GLUT-I, P-Akt, PI3K and HIF-I $\alpha$ protein levels in Hep-2 cells after treatment with cisplatin.

cancer. ${ }^{17}$ However, effect of the PI3K/Akt pathway on GLUT1expression and its involvement in the GLUT-1-induced chemoresistance of laryngeal carcinoma were unclear.

Several studies have investigated the potential mechanism of GLUT-1-induced chemosensitivity. GLUT-1 had been associated with markers of intrinsic chemosensitivity, such as glutathione-s-transferase- $\pi$, P-glycoprotein and multidrug resistance-associated protein. ${ }^{31}$ Shimanish et al showed that specific inhibition of GLUT-1 expression by siRNAs enhanced the sensitivity of oral squamous cell carcinoma to cisplatin, and the mechanism may involve HIF-1 $\alpha$-mediated GLUT-1 and glycolytic enzyme expression. ${ }^{18}$ However, another study showed that overexpression of GLUT-1 did not involve a corresponding increase in glycolytic enzyme levels regulated by HIF-1 but was associated with higher levels of phosphodiester related to phospholipid metabolism, suggesting that the mechanism of GLUT-1-regulated chemoresistance may involve increased cell turnover. ${ }^{32}$

In the present study, results showed that siRNA GLUT-1 significantly inhibited Hep-2 cell proliferation, apoptosis and numbers in G1/G2 and significantly enhanced cisplatin sensitivity in Hep-2 cells. LY294002 also enhanced cisplatin sensitivity in Hep-2 cells. Next, we investigated the mechanism by which GLUT-1 siRNA and LY294002 enhanced the cisplatin sensitivity of Hep-2 laryngeal carcinoma cells. The results revealed that there were no synergistic effects between LY294002 and cisplatin on the mRNA expression of GLUT-1, Akt, PI3K and HIF- $1 \alpha$ and there were no synergistic effects between siRNA ${ }_{\mathrm{GLUT}-1}$ and cisplatin on the
mRNA expression of GLUT-1, Akt and PI3K and there were synergistic effects between siRNA GLUT-1 $_{1}$ and cisplatin on the mRNA expression of HIF- $1 \alpha$.

\section{Conclusion}

This study showed that inhibiting GLUT-1, by a GLUT-1 siRNA, and PI3K/Akt, by the inhibitor Ly294002, could suppress the proliferation of Hep-2 alone and together with cisplatin synergistically, which demonstrated the potentials to treat laryngeal carcinoma in the future therapy. Additionally, the synergistic effect between LY294002 and cisplatin to suppress the proliferation of Hep-2 might not be from GLUT-1, Akt, PI3k and HIF-1 $\alpha$; the synergistic effect between GLUT-1 siRNA and cisplatin to suppress the proliferation of Hep-2 might not be from GLUT-1, Akt and PI3k and might be more or less related to HIF-1 $\alpha$.

\section{Acknowledgment}

This study was funded by Technology Department of Yinzhou, Ningbo City, Zhejiang Province, China (grant no 2014-99).

\section{Author contributions}

TJ and M-LZ designed the experiments and wrote the manuscript. JF carried out the experiments and participated in result interpretation; all authors revised the manuscript. All authors contributed to data analysis, drafting and revising the article, gave final approval of the version to be published, and agree to be accountable for all aspects of the work. 


\section{Disclosure}

The authors report no conflicts of interest in this work.

\section{References}

1. Siegel RL, Miller KD, Jemal A. Cancer statistics, 2017. CA Cancer J Clin. 2017;67(1):7-30.

2. Shen LF, Zhao X, Zhou SH, et al. In vivo evaluation of the effects of simultaneous inhibition of GLUT-1 and HIF-1 $\alpha$ by antisense oligodeoxynucleotides on the radiosensitivity of laryngeal carcinoma using micro 18F-FDG PET/CT. Oncotarget. 2017;8(21):34709-34726.

3. Wang M, Li X, Qu Y, Xu O, Sun Q. Hypoxia promotes radioresistance of CD133-positive Hep-2 human laryngeal squamous carcinoma cells in vitro. Int J Oncol. 2013;43(1):131-140.

4. Min JW, Kim KI, Kim HA, et al. INPP4B-mediated tumor resistance is associated with modulation of glucose metabolism via hexokinase 2 regulation in laryngeal cancer cells. Biochem Biophys Res Commun. 2013;440(1):137-142.

5. de Jong MC, Ten Hoeve JJ, Grénman R, et al. Pretreatment microRNA Expression Impacting on Epithelial-to-Mesenchymal Transition Predicts Intrinsic Radiosensitivity in Head and Neck Cancer Cell Lines and Patients. Clin Cancer Res. 2015;21(24):5630-5638.

6. Luo XM, Xu B, Zhou ML, et al. Co-Inhibition of GLUT-1 Expression and the PI3K/Akt Signaling Pathway to Enhance the Radiosensitivity of Laryngeal Carcinoma Xenografts In Vivo. PLoS One. 2015;10(11): e0143306.

7. Bao YY, Zhou SH, Lu ZJ, Fan J, Huang YP. Inhibiting GLUT-1 expression and PI3K/Akt signaling using apigenin improves the radiosensitivity of laryngeal carcinoma in vivo. Oncol Rep. 2015;34(4):1805-1814.

8. Yan SX, Luo XM, Zhou SH, et al. Effect of antisense oligodeoxynucleotides glucose transporter-1 on enhancement of radiosensitivity of laryngeal carcinoma. Int J Med Sci. 2013;10(10):1375-1386.

9. Luo XM, Zhou SH, Fan J. Glucose transporter-1 as a new therapeutic target in laryngeal carcinoma. J Int Med Res. 2010;38(6):1885-1892.

10. Melstrom LG, Salabat MR, Ding XZ, et al. Apigenin inhibits the GLUT-1 glucose transporter and the phosphoinositide 3-kinase/Akt pathway in human pancreatic cancer cells. Pancreas. 2008;37(4):426-431.

11. Zhang W, Zhang JQ, Meng FM, Xue FS. Dexmedetomidine protects against lung ischemia-reperfusion injury by the PI3K/Akt/HIF-1 $\alpha$ signaling pathway. J Anesth. 2016;30(5):826-833.

12. Chen B, Tan Y, Liang Y, et al. Per2 participates in AKT-mediated drug resistance in A549/DDP lung adenocarcinoma cells. Oncol Lett. 2017;13(1):423-428.

13. Pan F, Mao H, Bu F, et al. Sp1-mediated transcriptional activation of miR-205 promotes radioresistance in esophageal squamous cell carcinoma. Oncotarget. 2017;8(4):5735-5752.

14. Chang L, Graham PH, Ni J, et al. Targeting PI3K/Akt/mTOR signaling pathway in the treatment of prostate cancer radioresistance. Crit Rev Oncol Hematol. 2015;96(3):507-517.

15. Wang J, Wu Y, Gao W, et al. Identification and characterization of $\mathrm{CD} 133^{+} \mathrm{CD} 44^{+}$cancer stem cells from human laryngeal squamous cell carcinoma cell lines. $J$ Cancer. 2017;8(3):497-506.

OncoTargets and Therapy

\section{Publish your work in this journal}

OncoTargets and Therapy is an international, peer-reviewed, open access journal focusing on the pathological basis of all cancers, potential targets for therapy and treatment protocols employed to improve the management of cancer patients. The journal also focuses on the impact of management programs and new therapeutic agents and protocols on

Submit your manuscript here: http://www.dovepress.com/oncotargets-and-therapy-journal
16. Li D, Zhou L, Huang J, Xiao X. Effect of multidrug resistance 1/Pglycoprotein on the hypoxia-induced multidrug resistance of human laryngeal cancer cells. Oncol Lett. 2016;12(2):1569-1574.

17. Xu YY, Wu TT, Zhou SH, et al. Apigenin suppresses GLUT-1 and p-AKT expression to enhance the chemosensitivity to cisplatin of laryngeal carcinoma Hep-2 cells: an in vitro study. Int J Clin Exp Pathol. 2014;7(7):3938-3947.

18. Shimanishi M, Ogi K, Sogabe Y, et al. Silencing of GLUT-1 inhibits sensitization of oral cancer cells to cisplatin during hypoxia. J Oral Pathol Med. 2013;42(5):382-388.

19. Wang YD, Li SJ, Liao JX. Inhibition of glucose transporter 1 (GLUT1) chemosensitized head and neck cancer cells to cisplatin. Technol Cancer Res Treat. 2013;12(6):525-535.

20. Lin Q, Wang Y, Chen D, Sheng X, Liu J, Xiong H. Cisplatin regulates cell autophagy in endometrial cancer cells via the PI3K/AKT/mTOR signalling pathway. Oncol Lett. 2017;13(5):3567-3571.

21. Shi H, Pu J, Zhou XL, Ning YY, Bai C. Silencing long non-coding RNA ROR improves sensitivity of non-small-cell lung cancer to cisplatin resistance by inhibiting PI3K/Akt/mTOR signaling pathway. Tumour Biol. 2017;39(5):1010428317697568.

22. Liu T, Li R, Zhao H, et al. eIF4E promotes tumorigenesis and modulates chemosensitivity to cisplatin in esophageal squamous cell carcinoma. Oncotarget. 2016;7(41):66851-66864.

23. Ao Q, Su W, Guo S, Cai L, Huang L. SENP1 desensitizes hypoxic ovarian cancer cells to cisplatin by up-regulating HIF-1 $\alpha$. Sci Rep. 2015;5: 16396.

24. Pereira KM, Chaves FN, Viana TS, et al. Oxygen metabolism in oral cancer: HIF and GLUTs (Review). Oncol Lett. 2013;6(2):311-316.

25. Yoon SO, Jeon TJ, Park JS, et al. Analysis of the roles of glucose transporter 1 and hexokinase 2 in the metabolism of glucose by extrahepatic bile duct cancer cells. Clin Nucl Med. 2015;40(3):e178-e182.

26. Wang HJ, Hsieh YJ, Cheng WC, et al. JMJD5 regulates PKM2 nuclear translocation and reprograms HIF-1 $\alpha$-mediated glucose metabolism. Proc Natl Acad Sci U S A. 2014;111(1):279-284.

27. Chikamoto A, Inoue R, Komohara Y, et al. Preoperative High Maximum Standardized Uptake Value in Association with Glucose Transporter 1 Predicts Poor Prognosis in Pancreatic Cancer. Ann Surg Oncol. 2017; 24(7):2040-2046.

28. Chen X, Lu P, Zhou S, Zhang L, Zhao JH, Tang JH. Predictive value of glucose transporter-1 and glucose transporter-3 for survival of cancer patients: A meta-analysis. Oncotarget. 2017;8(8):13206-13213.

29. Zhou S, Wang S, Wu Q, Fan J, Wang Q. Expression of glucose transporter-1 and -3 in the head and neck carcinoma - the correlation of the expression with the biological behaviors. ORL J Otorhinolaryngol Relat Spec. 2008;70(3):189-194.

30. Wu XH, Chen SP, Mao JY, Ji XX, Yao HT, Zhou SH. Expression and significance of hypoxia-inducible factor- $1 \alpha$ and glucose transporter-1 in laryngeal carcinoma. Oncol Lett. 2013;5(1):261-266.

31. Mao ZP, Zhao LJ, Zhou SH, Liu MQ, Tan WF, Yao HT. Expression and significance of glucose transporter-1, P-glycoprotein, multidrug resistance-associated protein and glutathione S-transferase- $\pi$ in laryngeal carcinoma. Oncol Lett. 2015;9(2):806-810.

32. Evans A, Bates V, Troy H, et al. Glut-1 as a therapeutic target: increased chemoresistance and HIF-1-independent link with cell turnover is revealed through COMPARE analysis and metabolomic studies. Cancer Chemother Pharmacol. 2008;61(3):377-393.

\section{Dovepress}

patient perspectives such as quality of life, adherence and satisfaction The manuscript management system is completely online and includes a very quick and fair peer-review system, which is all easy to use. Visit http://www.dovepress.com/testimonials.php to read real quotes from published authors. 